1 Mather HM, Keen H. The Southall diabetes survey: prevalence of known diabetes in Asians and Europeans. Br Med $\mathcal{F}$ 1985;291:1081-4.

Ahuja MMS. Epidemiological studies on diabetes mellitus in India. In: Ahuja MMS, ed. Epidemiology of diabetes in developing countries. New Delhi: Interprint, 1979:29-38.

3 Gupta OP, Joshi MH, Dave SK. Prevalence of diabetes in India. In: Miller M, Bennett PH, eds.

Advances in metabolic disorders. Vol 9 . New York: Academic Press, 1978:147.65.

4 World Health Organisation study group. Diabetes mellitus. W'HO Tech Rep Ser 1985; No 727

(Acccepted 27 May 1986

Maulana Azad Medical College, New Delhi 110002, India

NARENDRA P S VERMA, MD, FAIID, associate professor of medicine

SUDARSHAN P MEHTA, MD, DPH, professor of social and preventive medicine SRIVENKATA MADHU, MD, registrar in medicine

Ealing Hospital, Southall, Middlesex UB1 3HW

HUGH M MATHER, MD, MRCP, consultant physician

Guy's Hospital Medical School, London SE1 9RT

HARRY KEEN, MD, FRCP, professor of human metabolism

Correspondence to: Dr Mather.

\section{Acute encephalopathy associated with campylobacter enteritis}

We report a case of acute encephalopathy accompanied by increased intracranial pressure in a child with campylobacter enteritis. This complication has not to our knowledge been previously reported.

\section{Case report}

A previously healthy 6 year old boy was admitted to the paediatric intensive care unit, confused after a history of being unable to speak for two days. Five days before admission he suffered from abdominal pain and diarrhoea followed by a headache and temperature of $39^{\circ} \mathrm{C}$. On admission he was afebrile and well nourished. His pulse was 50 beats/minute, sinus rhythm, blood pressure 100/60 $\mathrm{mm} \mathrm{Hg}$, and respiratory rate 20 breaths/minute without distress. There were no signs of meningeal irritation. On neurological examination the child looked drowsy but was arousable with bursts of irritability. He could follow only simple orders with oriented motor responses. He cried on painful stimuli but was unable to speak. His cranial nerves were intact, and sensory and cerebellar examination findings were normal. His deep tendon reflexes were hyperactive, and bilateral Babinski's sign was elicited. Funduscopic examination showed no papilloedema.

Complete blood count showed 9000 white blood cells $/ \mathrm{mm}^{3}$ with norma differential count, haemoglobin concentration $110 \mathrm{~g} / \mathrm{l}$, and 200000 platelets $\mathrm{mm}^{3}$. Biochemical values were all within the normal range. Tests on blood gases, coagulation studies, and urine analysis yielded normal results. The cerebrospinal fluid was initially clear with a pressure of $260 \mathrm{~mm} \mathrm{Hg}$, but a brisk movement of the child during lumbar puncture caused it to become macroscopically bloody; it contained 70 white blood cells $/ \mathrm{mm}^{3}$, of which $80 \%$ were monocytic and $20 \%$ polymorphonuclear. Glucose concentration was $5.0 \mathrm{mmol} / \mathrm{l}(90 \mathrm{mg} / 100 \mathrm{ml})$ concomitant blood glucose concentration was $6 \cdot 1 \mathrm{mmol} / \mathrm{l}(110 \mathrm{mg} / 100 \mathrm{ml})$. Results of all tests and cultures for bacteria and viruses were negative, except for repeated stool cultures, which grew Campylobacter fetus, confirmed by serotyping as $C$ fetus subspecies jejuni serotype 1,18 .

An electroencephalogram showed no $\alpha$ rhythms but instead high voltage diffuse $\delta$ activity $2-3 \mathrm{H}$ admixed with a few $\theta$ waves, consistent with acute encephalopathy. Computed tomography of the brain showed oedema with smal compressed ventricles.

He was treated with dexamethasone and mannitol but no antibiotics. After three days in hospital his condition had greatly improved and he could utter a few words. After eight days he resumed his normal behaviour and speech, and neurological examination was normal. Repeated computed tomography of the brain on the fifth day after admission showed normal ventricle size and no . The electroencephalogram returned to normal three weeks after his illness began, and stool cultures contained no campylobacters.

\section{Comment}

Over the past two decades Campylobacter has been recognised as a major cause of diarrhoeal disease in children. ${ }^{12}$ Extraintestinal manifestations of campylobacter enteritis, most commonly presenting as bacteraemia without localised infection, occur mainly in early infancy and compromised adults with underlying systemic diseases. ${ }^{3}$ In a review of 247 cases Schmidt et al found that the central nervous system was affected in $12 \%$ of cases of extraintestinal disease. ${ }^{3}$

Besides seizures, a well documented neurological complication of campylobacter enteritis, ${ }^{4}$ effects on the central nervous system include meningitis , meningoencephalitis, stroke, subarachnoid haemorrhage, subdural em- pyema, and the Guillain-Barré syndrome, ${ }^{3}$ all of which are associated with invasion of the central nervous system by the bacteria themselves or with localised neurological disease. The pathogenesis of systemic or extraintestinal campylobacteriosis is unclear. Neurological expression has been attributed to a neurotoxin produced by the bacteria, a process similar to that which causes shigella gastroenteritis. This theory is still controversial and has to be proved.

Most extraintestinal neurological manifestations of campylobacter infection are associated with the subspecies intestinalis, whereas in our case $C$ fetus subspecies jejuni was isolated. It has been recently reported that this subspecies can also affect the brain, and our report supports this observation. Infection with Campylobacter should be considered when neurological symptoms such as seizures or increased intracranial pressure complicate gastrointestinal disease.

We express our appreciation to Dr P Lerman for interpretation and follow up of the electroencephalogram, and to the staff of the Campylobacter Reference Laboratory, Israeli Ministry of Health, for confirmation of serotype.

1 Karmali MA, Fleming PC. Campylobacter enteritis in children. J Pediatr 1979;94:527-33

2 Rettig PG. Campylobacter infection in human beings. I Pediatr 1979;94:855-64.

3 Schmidt U, Chmel H, Kaminski Z, et al. The clinical spectrum of Campylobacter fetus infections: report of five cases and review of literature. Of Med 1980;196:431-42.

Havalad S, Chapple MJ, Kahakachchi M, Hargraves DB. Convulsions associated with campylobacter enteritis. Br Med $\mathcal{f} 1980 ; 280 \cdot 984-5$.

Norrby R, McCloskey RV, Zackrisson G. Meningitis caused by Campylobacter fetus spp jejuni. $\mathrm{Br}$ Med f 1980;280:1164.

(Accepted 2 fune 1986)

Department of Pediatrics A, Beilinson Medical Center, Petah Tiqva 49100 Israel

I LEVY, MD, house physician

Y WEISSMAN, MD, senior physician

Pediatric Intensive Care Unit, Beilinson Medical Center, Petah Tiqva 49 100, Israel

Y SIVAN, MD, senior physician

J BEN-ARI, MD, house physician

T SCHEINFELD, MD, head of unit

Correspondence to: Dr Sivan.

\section{Lack of antibody to HTLV-I and HIV in patients with multiple sclerosis from France and French West Indies}

Recent data have suggested that human retroviruses have an aetiological role in some acute and chronic neurological diseases. Human immunodeficiency virus (HIV; formerly known as lymphadenopathy associated virus or human T cell lymphotropic virus type III) was detected in brain tissue and isolated from cerebrospinal fluid of patients with encephalopathy related to the acquired immune deficiency syndrome. ${ }^{1}$ We observed a high prevalence $(60 \%)$ of antibodies to human T cell lymphotropic virus type I (HTLV-I) in serum from patients with tropical spastic paraparesis, a neuromyelopathy common in tropical areas where HTLV-I is endemic. ${ }^{2}$ These findings were confirmed in both serum and cerebrospinal fluid from patients with tropical spastic paraparesis from Jamaica and Columbia. ${ }^{3}$ Recently, Koprowski et al reported that American and Swedish patients with multiple sclerosis had antibodies that cross reacted with HTLV-I or HIV polypeptides and that cells from the cerebrospinal fluid of four out of eight patients contained sequences related to HTLV-I. ${ }^{+}$We report the results obtained when we tested serum from 55 patients with multiple sclerosis from two other geographical areas.

\section{Patients, methods, and results}

We studied 96 patients with neurological disease from Paris hospitals (48 with multiple sclerosis, 10 with amyotrophic lateral sclerosis, and 38 with other neurological diseases) and seven black patients with multiple sclerosis from Martinique (French West Indies). All serum samples were tested by enzyme linked immunosorbent assay for HTLV-I (Biotech, using disrupted virions as antigen) and for HIV (Elavia-Pasteur). None of the samples was positive for antibodies to HTLV-I (estimated by the ratio in the assay and the baseline value) or to HIV. Furthermore, the mean reactivity levels of HTLV-I in multiple sclerosis, amyotrophic lateral sclerosis, and the other neurological diseases did not differ significantly when tested by one way analysis of variance. 